\title{
Studies on the Development of Children's Social Interaction and the Family Relations
}

\author{
Keyan Zhao \\ Liaoning Financial Vocationgal College, Shenyang 110122, China \\ E-mail: 570106000@qq.com
}

\begin{abstract}
Abtract: With the rapid development of society and economy, there are growing problems in the relations among families. There have also been children's aggressive behaviours in some families. It is important for people to deal with the relations with children and let them grow healthily both physically and mentally. This article mainly focuses on the three parts of personality, moral development, the three stages of language development, and the possible reasons and motivations. In the end, the author provides the suggestions on how to improve the problems. It has practical significance for related families.
\end{abstract}

Keywords: the development, children's social interaction, the family relations

\section{Development of children's social interaction over the first year of life}

The most important relationship a child forms during the first year of life is the special bond between the infant with his/her parents or the person who look after them. Macfarlane (1975) concluded after investigation that a ten-days-old infant could recognise his mother by smell alone ${ }^{[1]}$.

Infants don't really do much except crying, eating and sleeping. Smiling is one of the first ways through which they interact with adults. After conducting controlled experiment, Ahrens discovered an infant will smile at anyone who approaches and interacts with him from two to seven months old. In the second part of the infant's life, Spitz found out that the infant don't often smile at a stranger. That is because they have developed a specific attachment with their parents or the ones who look after them.

\section{The importance of family relationships to developing children and the difference between family care and group care environments}

\subsection{The importance of family relationship to developing children}

The family relationship is very important to developing children. The family has a wide range of effects on a child. The more people there are in the family, the greater the number of relationships possible between family members. Each relationship plays an important role in a child's life as follows:

(1) Father's role: the intensity of the father's attachment to his child is determined by three factors (Chibucos and Kail-1981):

(a) The father's sensitivity to the baby's signals

(b) His playfulness with the baby

(c) The amount of time he spends in face-to-face interaction with the baby

It is very similar to the mother-child relationship, however, fathers interact more with boys than with girls and they stimulate them more. The most critical roles which the father plays are in the development of gender roles.

(2) Siblings (Brothers and sisters): Siblings play a more complex and important role to a developing child. Siblings play a vital role in modelling behaviour as Lawson and Ingleby (1974) investigated and found that 12 month old children spent as much time with their older siblings as they did with their mothers and more than with their fathers. ${ }^{[2]}$ Siblings also play an important role in influencing the intellectual development of a child. Dunn and Kendrick (1982) observed that when children played with their siblings, their play was more advanced compared to when they played with their peers and their parents. ${ }^{[3]}$ Dale (1983) noted advanced imaginative play between 2 years and their siblings.

(3) Peer relationship is important to the children as the infants at 6 months old display the interactions between them. The frequency and complexity of infant-infant interactions increases as they grow. 


\subsection{The difference between family care environments and group care environments}

Most countries have a norm for a child to be raised in a single small family unit, while some other countries and societies have a long history of communal child-rearing, such as China, Russia and Reseal. In those countries, mothers are encouraged to work while their children are cared for in state-run institutions. There are a lot of researches done about Maternal Employment. In summary, Yarrow found that women who were not working but preferred to work were the least adequate in their maternal behaviours. They had most difficulty with control, had least confidence in themselves and gained less emotional satisfaction in their relationship with their children; in the United States, Kagen found little difference between children placed in day-care centers and those raised at home in the amount of protect, seek closeness to the mother when upset. Bee states there are no negative effects when a child is cared for in a day-care center provided it is run by trained personnel with a high staff-child ratio.

Bowlby (1977) stresses the importance of the family to a developing child. He points out that in no other relationship do human beings place themselves so unreservedly and continuously at the disposal of others. ${ }^{[4]}$ Rutter agrees that the quality and amount of maternal care provided in the average institution is much worse than the average family. He believes that the greatest caution should be taken in placing a child in long term institutional care but a bad home should not be automatically preferred to a good institution. He stresses the need to examine the quality of parental care and its stability before putting the children in care: foster care, adoption and residential nurseries.

\section{Three stages of language development}

All Children follow the same general sequence of three stages of language development.

\subsection{The pre-linguistic or prattle stage}

This phase lasts for most of the child's first year. There are several different milestones within this stage.

(a) 2 Months old

The child is capable of producing all linguistic sounds the human voice is capable of. These same sounds are uttered by children all over the world.

(b) 5 Months old

Pre-linguistic sounds begin to be organized when the child starts to prattle or babble. It involves the repetition of syllable-like sounds. This is an innate ability.

(c) 6-12 Months old

Babbling reaches its peak at about 9-10 months old. This increase in babbling takes place alongside an increasing use of gestures.

\subsection{One-word sentence stage}

The first word generally appears when the child is around 12 months old. It is only when the sound stands for something definite which means the same to the speaker and hearer that we can say that those sounds are in fact "a word". The first words are usually nouns followed by verbs, adjectives, pronouns and adverbs. These earliest words are short ones and are often called one-word sentences or holophrases. Single word often performs the function of a sentence.

\subsubsection{The growth of vocabulary}

The growth of a child's vocabulary is extremely slow at the beginning only about 20 words by 18 months old. However, at about two to two and half years old, there is a rapid spurt in the size of his vocabulary to the age of three years old when the rate of acquisition slows down again. The estimates of the extent of a child's vocabulary at each stage is widely different because there are different methods of acquiring data but also because there are large individual differences between the speeds at which different children extend their vocabularies. For example, one child may utter his first word at 10 months old whilst another at 18 months old. Both are in the normal range.

\subsection{Several words combined}

An important change takes place in the child's use of language when he has acquired around 200 words at the age of about two to two and half years and he begins to combine these in 2-word sentences.

Madorah Smith had calculated the length of sentences used at different ages but large variations from this do normally occur. When a child begins to use 2-word sentences, he does not just randomly link 2 words together. This is done in a very specific way. Roger Brown used naturalistic observation to conduct a longitudinal study, he concluded that child omits and retains words when imitating sentences. This selection is highly systematic. Generally speaking nouns, verbs and less often adjectives, are likely to be retained with inflections, auxiliary verbs and articles, prepositions and conjunctions being omitted. Brown calls this type of speech Telegraphic speech. Telegraphic speech communicates very well because it retains 
the high-information words and drops the low-information words. Differential stress theory can alternatively explain why young children retain only certain words in imitation adult sentence. Brown noticed that adults seemed to imitate more often than did the children themselves. Such adult imitations are usually expansions. From the mother's point of view, an expansion is a kind of communication check, as if to say, "Is this what you mean?" Brown believes that the clearest evidence a very young child can give that he is working out the structure of language is when he produces "unlawful" utterance. Such unlawful utterances seem to be overgeneralisations of the regular forms of the past and the plural. ${ }^{[5]}$

\subsection{There are two theories of language development}

\subsubsection{Reinforcement or learning theory}

Explanations of language acquisition have been proposed which are based on operant conditioning principles as described by Skinner (1971). ${ }^{[6]}$ Skinner believes that when a child is first learning single words, as part of his random babbling he will produce a sound that approximates an actual word, and the mother will then reward or positively reinforce this apparently successful approximation to the actual word by hugging him, saying "good boy" and so on. This theory explains how children learn to label objects and how children acquire grammar. There is a fundamental problem with this approach to language acquisition which is the emphasis its place on the role of parental and social approval. Reinforcement theory is also unable to give a satisfactory explanation of how children come to combine the words in telegraphic sentences, and it is unable to explain the mistakes children make in learning language.

\subsubsection{Innate theory}

Chomsky (1968) believes there is a considerable innate pre-disposition to language. ${ }^{[7]}$ Chomsky proposed that children use a generative transformational grammar which moulds together what is heard (called the surface structure of a sentence) and what is meant (the deep structure). Chomsky argues that the existence of several language universal; adult speech is too poorly structured and impaired in performance for children to learn from it; speed of acquisition indicates the child must be pre-programmed to learn language. There is little doubt that children come to the language learning task with some sort of innate equipment. There is also anatomical and physiological evidence that there are language areas in the cortex of the brain. If there is any damage to these specific areas, the individual's language ability is affected in very specific ways.

\section{The stages of cognitive development suggested by Piaget and state what methodological problems have been used to criticise the theory}

Jean Piaget and his theory of the intellectual and cognitive development of the child has been a major influence on education in the western world. Piaget believes that intellectual development occurs as the child is constantly trying to make sense of his own world and adapt to his environment. In his theory of cognitive development, Piaget describes the development of the child's mental structures which he calls schemas. Piaget views intelligence as a type of mental activities which enables the child to constantly adapt to his environment. ${ }^{[8]}$

\subsection{Piaget's stages of cognitive sevelopment}

\subsubsection{Sensory-motor period: Birth to 2 years}

During the sensory-motor period, infants construct an understanding of the world by coordinating sensory experiences such as seeing and hearing with physical, motoric actions. Infants gain knowledge of the world from the physical actions they perform on it. As a result of the processes of assimilation and accommodation, the infant's simple schemas of sucking, grasping, etc become more differentiated and more complex. An infant progresses from reflexive, instinctual action at birth to the beginning of symbolic thought toward the end of the stage.

This period of sensory-motor intelligence can be sub-divided as follows:

(1) 0-6 Weeks The only schemas are ready-made reflexes.

(2) 6 Weeks to 4 or 5 Months The is the period of primary circular reactions.

(3) 4-8 or 9 Months The is the period of secondary circular reactions.

(4) 9-12 Months Coordination of secondary circular reactions stages

(5) 12-18 Months Tertiary circular reactions, novelty, and curiosity

(6) 18-24 Months Internalization of Schemes

\subsubsection{Pre-operational period: 2-7 years}

During this period, there is an important change in the way children think when they learn how to talk as their mental schemas become symbolic ones. During this stage, children do not reason logically, they demonstrate animism, and they are limited to looking at things only from their own point of view, which is called egocentrism. Beyond the age of 7 , 
children show an increasing ability to decentre and take into account other people's point of view. Egocentrism in a way can explain early animism because the child assumes that everybody and everything must have feelings and intentions like his own. Children at the pre-operational stage are also very tied to the appearance of things. Piaget conducted experiments into various types of conservation including Conservation of continuous quantity and Conservation of mass or quantity. Children generally master the conservation tasks as follows:

(1) Conservation of continuous quantity, mass or substance at 6 or 7 years.

(2) Conservation of weight at 9 or 10 years

(3) Conservation of volume at 11 or 12 years.

\subsubsection{Operational period}

(a) Concrete operations 7 to 11 years

At around 6 or 7 years the child's thinking becomes more logical and mathematical. They start to succeed at conservation tasks because their thoughts are now reversible and they can perform operations; the children are now attentive to several different kinds of information at the same time. However, children at this stage can only think in terms of real world objects and events. They use inductive logic, i.e. they can form general principles from their own actual experience.

(b) Formal operations 11 years to adulthood

At this stage, individuals move beyond concrete experiences and begin to think abstractly, reason logically and draw conclusions from the information available, as well as apply all these processes to hypothetical situations. Children acquire a different approach to problem-solving. They can use deductive logic so they are able to impose their own logical structure of hypothetical possibilities on a problem. Formal operational thinkers will systematically consider all possible hypotheses in order to come to a solution.

Piaget believes that all children go through the same stages of cognitive development in the same order. The sequence of stages is invariant.

\subsection{Methodological problems used to criticize Piaget's theory}

(1) Piaget relied heavily on clinical interviews. In conducting clinical interviews there is always the danger that the experimenter may lead the child to say things which he would not otherwise have said.

(2) Flavell believes that Piaget goes beyond the evidence obtained when interpreting his data.

(3) Wohwill says that Piaget's data illustrates his theory rather than confirming it.

\section{Three parts of personality outlined by Freud}

Freud believed that sex and aggression were the basic forces motivation behavior and libido was the instinctual source of all energy which was present from earliest childhood. He also believed that the roots of adult personality could be found in early childhood experience.

In Freud's theory, personality consisted the following three parts.

\subsection{The Id}

Id is the most primitive and original source of personality. It consists of the basic instinctual drives of sex and aggression and it is the central source of libido. It operates on the pleasure principle, seeking immediate gratification of all primitive, pleasure-seeking impulses. It tries to obtain pleasure at all costs, i.e. form a mental image or hallucination of its desire which is called wish fulfillment.

\subsection{The ego}

Ego obeys the reality principle, which delays fulfillment until appropriate environment conditions are found. The ego operates by secondary process thinking which is realistic and logical and plans how to achieve satisfaction.

\subsection{The superego}

Superego is the last personality structure to develop and it governs moral behavior. Superego consists of the conscience and the ego-ideal. Conscience punishes by making the person feel guilty and the ego ideal rewards by making him feel proud.

In a normal person, the three parts work together to give integrated behavior. The three parts of the personality are at odds some times because the ego puts off gratification of instinctual needs that the id requires, and behavior falls short of the standards set by the superego. 


\section{Possible reasons why a child behaves aggressively}

Aggression is an aggressive act which causes injury or anxiety to others or the destruction of property.

The reasons why a child might behave aggressively are:

(1) Freud believes that aggression is instinctive and we must find acceptable ways of expressing this. ${ }^{[9]}$

(2) Lorenz (2002) also believes that aggression is instinctive and we have an innate, spontaneous readiness to fight. ${ }^{[10]}$

(3) Biological theory believes that there is a relationship between aggressive behavior and biochemistry (psychology). Aggression is not automatically produced by stimulation to the brain, but the aggression-center may be stimulated and the higher centers in the brain decide on exactly which response will be initiated.

(4) Frustration-Aggression Hypothesis states that aggression is a reaction to frustration. But it cannot apply equally to all children because there is a wide range of individual differences in reactions to frustration.

(5) Aggression as a learned response. Social learning theorists believe that aggression is no different from any other learned response. It can be learned by observation and imitation. The more often aggression is reinforced; the more likely it is to occur. Peers are a frequent source of reinforcement for aggressive behavior even from a very young age. Home situation can also encourage aggressive behavior.

(6) Imitation of aggression-Experiment carried by Bandura showed the children will imitates aggressive behavior.

(7) Televised violence-a number of studies have investigated the relationship between viewing violent television programmes and aggressive behavior and it does show a relationship between them.

\section{Conclusion and suggestions}

Family relations is going to have a huge impact on the parents and children. The children are the ones who will be greatly affected. From the psychologist's point of view, they are denied the accesses to the wider opportunities to others, therefore, the chances for them to develop in intelligence, language skills, motor skills, and social skills are important.

We hope that parents will take careful consideration on various factors especially the development of the children.

(1) Children understand their own characteristics and develop self awareness.

(2) Parents learn to listen and expression of children, and develop good interaction skills.

(3) Children grasp emotions and develop the ability to relieve stress.

(4) Understand , support others and develop empathy.

(5) Carry effective problem-solving skills.

(6) Avoid aggressive words and deeds and develop self-discipline.

\section{References}

[1] A. Macfarlane. Olfaction in the development of social preferences in the human neonate. Ciba Found Symp. 1975; 33:103-117. doi:10.1002/9780470720158.ch7.

[2] Annette Lawson, David Ingleby. Daily routines of pre-school children. Effects of age, birth order, sex and social class, and developmental correlates. Psychological Medicine. 1974; 4: 399-415.

[3] Judy Dunn, Karol Kendrick. Siblings and their mothers. Developing relationships within the family. In M. Lamb \& B. Sutton-Smith (Eds.), Sibling Relationships. Their nature and significance across the lifespan. 1982; 39-60. Hillsdale, NJ: Lawrence Erlbaum.

[4] John Bowlby. The making and breaking of affectional bonds. British Journal of Psychiatry. 1977; 3: 201-210.

[5] Roger Brown. Child's Native Language 1, Human Communication: Theoretical Explorations. 2015; 27: 123.

[6] Burrhus F Skinner. Operant conditioning. The encyclopedia of education. 1971; 7: 29-33.

[7] Noam Chomsky. Language and Mind. New York: Harcourt, Brace \& World. 1968.

[8] William Huitt, John Hummel. Piaget's theory of cognitive development. Educational psychology interactive. 2003; $3(2): 1-5$

[9] Hans W Loewald. Freud's conception of the negative therapeutic reaction, with comments on instinct theory. Journal of the American Psychoanalytic Association. 1972); 20(2): 235-245.

[10] Konrad Lorenz. On aggression Psychology Press. 2002. https://books.google.co.uk/books?hl=en\&lr=\&id=rIVK7wu. 